\title{
A Note on Translations
}

Unless otherwise indicated, all translations are my own. When I first cite the English title of a German-language work, an asterisk indicates that, as far as I am aware, the cited work has not yet been translated into English. When published translations exist of cited works of both primary and secondary literature, I provide the bibliographic information in the footnotes. I have also provided a list of "Primary Works in English Translation for Further Reading." This list contains published translations of the works cited in the current study by the Germanlanguage writers of imaginative literature who are the focus of Ambivalent Literary Farewells. In those few instances where I drew upon published translations rather than providing my own translations, those works are listed in the bibliography, either primary or secondary, and not in the list of "Primary Works in English Translation for Further Reading." 
